\title{
Perioperative Pain Management With Bilateral Pecto-intercostal Fascial Block in Pediatric Patients Undergoing Open Cardiac Surgery
}

\author{
Yang Zhang ${ }^{1}$, Xuekang Zhang ${ }^{1}$, and Shibiao Chen ${ }^{1}$ \\ ${ }^{1}$ First Affiliated Hospital of Nanchang University
}

February 22, 2022

\begin{abstract}
Purposes: Pediatric open cardiac surgical patients usually suffer from acute pain after operation. The aim of this study was to investigate the effect of bilateral PIFB in children undergoing open cardiac surgery. Methods. A group of 110 pediatric patients were randomly allocated to either receive bilateral PIFB (PIF group) or no nerve block (SAL group). The primary endpoint was postoperative pain at rest and exercise. Secondary outcomes included time to drain removal, time to extubation, intraoperative and postoperative fentanyl consumption, time to first feces, length of stay in the ICU and the length of hospital stay. Results. The trends of MOPS were significantly higher at 24 hours after operation both at rest and during coughing in SAL group compared with PIF group. The PIF group reported significantly less intraoperative and postoperative fentanyl consumption. Time to extubation, time to first flatus, length of stay in the ICU and the length of hospital stay were significantly decreased in the PIF group. Conclusion. Bilateral PIFB in pediatric open cardiac surgical patients provide effective analgesia and reduce the length of hospital stay .
\end{abstract}

\section{Hosted file}

Manuscript.doc available at https://authorea.com/users/461857/articles/557445-perioperativepain-management-with-bilateral-pecto-intercostal-fascial-block-in-pediatric-patientsundergoing-open-cardiac-surgery 
FIGURE 1. Patient flow diagram.

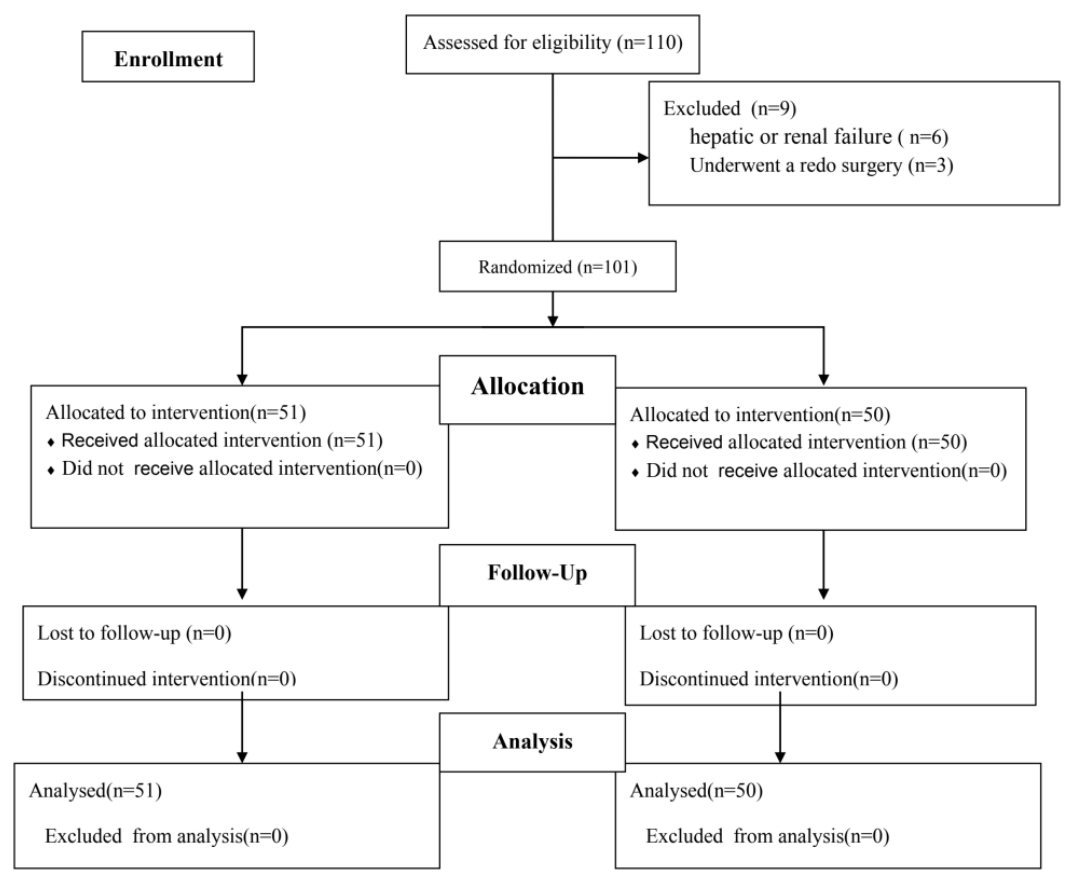



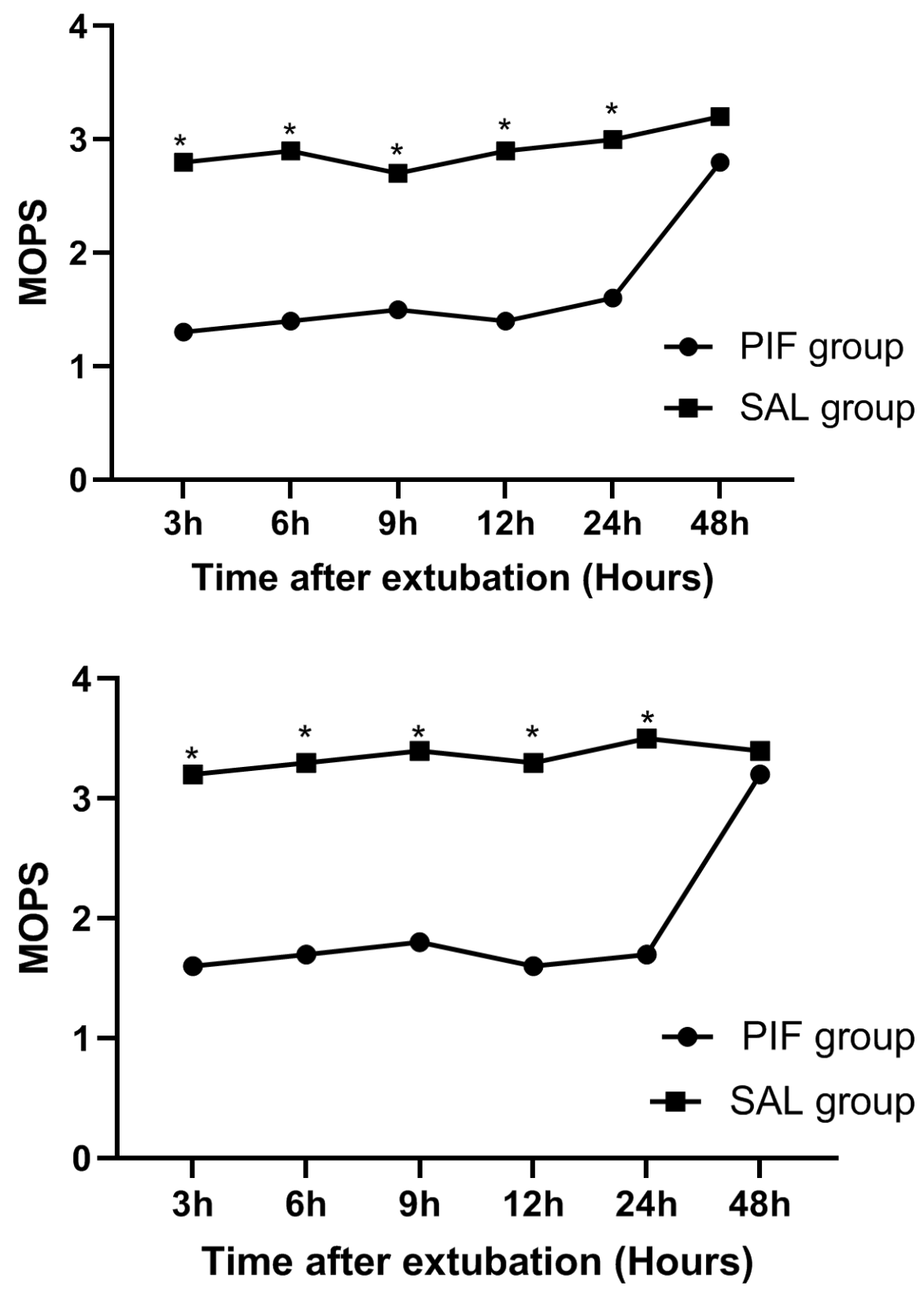

Hosted file

Figure lengend.doc available at https://authorea.com/users/461857/articles/557445perioperative-pain-management-with-bilateral-pecto-intercostal-fascial-block-inpediatric-patients-undergoing-open-cardiac-surgery

Hosted file

Table.doc available at https://authorea.com/users/461857/articles/557445-perioperativepain-management-with-bilateral-pecto-intercostal-fascial-block-in-pediatric-patientsundergoing-open-cardiac-surgery 